\title{
Observaciones románticas
}

\author{
Juan Carlos Saravia Vargas
}

\section{Ardilla en la rama alta}

on tu vida desafías constantemente a la muerte,] oh, maestra trapecista confiada, en las alturas te bamboleas creyendo en tu suerte]

y asciendes para escapar de mi mirada. Te detienes, lejos, en un frágil punto de apoyo.]

¿No taladra el vértigo en tu corazón un hoyo?]

me pregunto al verte trepar el árbol, hábil ardilla,]

pues el viento que en el suelo las hojas rastrilla]

en lo alto ha de presentarte algún escollo a ti, que al borde de una fina rama pendes.]

Me pregunto si acaso comprendes la razón por la cual las hojas en la rama faltan;]

¿las arrancó implacable la tormenta?

Mira las grietas que en la corteza resaltan:]

trae la ciudad al árbol una muerte lenta.

Cruje tu asiento con el viento frío;

eres un punto que rasga el vacío;

alcanzas una rama baja, sacudes tu cola altiva,]

e indiferente, tras la corteza, desapareces esquiva.]

\section{Caminante triste}

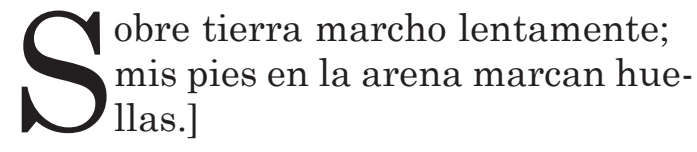

Caminante, mira arriba atentamente, el firmamento alumbrado por centellas: quienes se aman, sus pasiones afuellan y con alas que el amor puso en sus lomos al fin libres, al cielo suben.

Abandona ya la vida solitaria de los lobos; Vuela, alcanza también tú las nubes. ¿Por qué habrías de quedarte acá abajo?

Me muevo pesadamente, cual escarabajo,]

pues una noche clara, buscando luces bellas,]

hacia la luna volé con trabajo

y mi ilusión rasgaron cruelmente las estrellas.]

Por tanto hoy, triste, en la tierra dejo sendas;]

ya mis pies no se lastiman con las piedras.] 


\section{Sobre la roca}

$\bigcirc$ obre la roca contemplo el océano absorto, sin tiempo, en su apasionado vaivén:]

Eterno baile de olas, espuma clara, compás de amor que cautiva mi ser.

Entona la marea sensual estrofa y antiestrofa,]

flujo y reflujo, perfecta sincronía que invita,]

caricias en la playa de manos suaves, dedos sutiles, aguas de malaquita.

Es tu secreto susurro de mar escondido en blancas arenas de tierras ardientes donde surcan el cielo en grupos alados deseos callados, cual gaviotas hacia el sol poniente, $\mathrm{y}$ al apagarse la tarde ambarina con la noche se alejan, envueltos en aroma de brisa marina.

\section{Noches de tormenta}

$\mathrm{M}$ e gustan las noches cuando llueve fuerte]

empapado;]

el mundo, por fin amigo, llora mi suerte: mis lágrimas con las del cielo se han juntado.]

Me gustan las noches oscuras con tormenta]

cuando rugen los cielos por rayos azotados,]

pues los temores que mi corazón amedrentan]

con cada trueno saltan y se alejan asustados.]
Me gustan esas noches tétricas, encapotadas,]

que al ver la soledad mi corazón devorando]

vierten furiosas cubetas en mi alma atribulada]

y la usurpadora huye a nado, resoplando.

Oscuridad y tormenta disuelven formas y penas,]

por tanto, amo las noches negras sin estrellas:]

indiferente, el día inyecta dolor en mis venas,]

mas, sin luz, su aguja en mí no deja huellas.]

\section{Competencia por la vida}

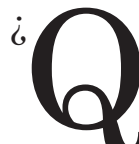

uién les dio la señal?

No podría decirlo, pero todos, tras larga espera, en fantástica sincronía ahora nadan agitando su fuerte cola con prisa aunque, al final, solamente uno se hará con el codiciado premio, redondo, dispuesto y merecido en medio de un medio líquido. El vencedor penetrará primero poniendo fin a la competencia; girará y girará en celebración primitiva, empapándose con el jugo de la vida.

Los otros, vencidos, intentarán tomar parte, pero será ya muy tarde: el placer de la victoria pertenece tan sólo al primer cocodrilo que alcanza al jabalí cruzando el río. 